Significance/Contribution to the Field Although there are problems that remain to be solved in order to economically manufacture button cell batteries and/or housings that have a reduced hazard for electrical burns, this research demonstrates that feasible solutions to this issue are possible.

\section{DESIGN STRATEGIES TO MITIGATE THE HAZARD OF BUTTON CELL BATTERY ELECTRICAL BURN INJURIES}

doi:10.1136/injuryprev-2012-040590i.13

G Rider, R Altkorn, D Stool, X Chen, S Milkovich. Intertek, USA

Background Children's exposure to button cell batteries is increasing with the greater number of toys and other consumer products requiring their use. Children frequently mouth objects and may inadvertently swallow them. Ingestion of batteries or insertion into the nasal passages or external auditory canals may lead to serious injury resulting from burns caused by electric discharge.

Aims/Objectives/Purpose A variety of hazard mitigation strategies may be utilised to reduce the potential for these injuries, including decreasing accessibility of the batteries or redesign of the batteries themselves. Hazard mitigation strategies are discussed and evaluation methods presented.

Methods Data on battery injuries is reviewed and various existing reduced hazard battery modalities are identified. Methods of assessing hazard are discussed. Comparative potential release of current between battery/housing designs has been measured using animal cadaver tissue.

Results/Outcomes Existing designs of batteries consistently cause burns to animal cadaver tissue of varied severity depending on power and surface contact area. 